\title{
Persistent pain in a community-based sample of children and adolescents: Sex differences in psychological constructs
}

\author{
Samantha Fuss MA, M Gabrielle Pagé MA, Joel Katz PhD
}

\begin{abstract}
S Fuss, MG Pagé, Joel Katz. Persistent pain in a community-based sample of children and adolescents: Sex differences in psychological constructs. Pain Res Manage 2011;16(5):303-309.
\end{abstract}

BACKGROUND: Very few studies have investigated the psychological factors associated with the pain experiences of children and adolescents in community samples.

OBJECTIVES: To examine the lifetime prevalence of, and psychological variables associated with, persistent pain in a community sample of children and adolescents, and to explore differences according to sex, age and pain history.

METHODS: Participants completed the Childhood Anxiety Sensitivity Index (CASI), the Child Pain Anxiety Symptoms Scale (CPASS), the Multidimensional Anxiety Scale for Children-10 (MASC-10), the Pain Catastrophizing Scale for Children (PCS-C) and a pain history questionnaire that assessed chronicity and pain frequency. After research ethics board approval, informed consent/assent was obtained from 1022 individuals recruited to participate in a study conducted at the Ontario Science Centre (Toronto, Ontario).

RESULTS: Of the 1006 participants (54\% female, mean $[ \pm$ SD] age $11.6 \pm 2.7$ years) who provided complete data, $27 \%$ reported having experienced pain that lasted for three months or longer. A $2 \times 2 \times 2$ (pain history, age and sex) multivariate ANOVA was conducted, with the total scores on the CASI, the CPASS, the MASC-10 and the PCS-C as dependent variables. Girls with a history of persistent pain expressed higher levels of anxiety sensitivity $(\mathrm{P}<0.001)$ and pain catastrophizing $(\mathrm{P}<0.001)$ than both girls without a pain history and boys regardless of pain history. This same pattern of results was found for anxiety and pain anxiety in the older, but not the younger, age group.

CONCLUSIONS: Boys and girls appear to differ in terms of how age and pain history relate to the expression of pain-related psychological variables. Given the prevalence of persistent pain found in the study, more research is needed regarding the developmental implications of persistent pain in childhood and adolescence.

Key Words: Children; Persistent pain; Psychosocial factors; Sex differences

$\mathrm{E}^{\mathrm{B}}$ idemiological research has shown persistent and recurrent pain to highly prevalent among children and adolescents. Studies conducted within community settings in Europe estimate that between $25 \%$ and $37 \%$ of children report experiencing nonmalignant pain lasting for three months or longer, with nearly one-half and two-thirds of this group still reporting pain one and two years later, respectively (1-3). A recent Canadian school-based study (4) found that $60 \%$ of children between nine and 13 years of age reported having at least one type of recurring pain and $5 \%$ reported experiencing pain that lasted for longer than a few months and that was present at the time of the study. While a sizable proportion of youth report experiencing persistent pain, Huguet and Miro (1) found that only a small proportion of these individuals are severely impaired by it. Pain chronicity among youth differs according to sex, with girls more likely to report

\section{La douleur persistante dans un échantillon communautaire d'enfants et d'adolescents : les différences de constructs psychologiques selon les sexes}

HISTORIQUE : Très peu d'études ont porté sur les facteurs psychologiques associés aux expériences de douleur d'enfants et d'adolescents provenant d'échantillons communautaires.

OBJECTIFS : Examiner la prévalence à vie et les variables psychologiques de la douleur persistante dans un échantillon communautaire d'enfants et d'adolescents et explorer les différences selon le sexe, l'âge et les antécédents de douleur.

MÉTHODOLOGIE : Les participants ont rempli l'indice de sensibilité à l'anxiété de l'enfance (CASI), l'échelle de symptômes d'anxiété liés à la douleur chez l'enfant (CPASS), l'échelle d'anxiété multidimensionnelle pour les enfants-10 (MASC-10), l'échelle de catastrophisation de la douleur chez les enfants (PCS-C) et un questionnaire d'antécédents de douleur qui évaluait la chronicité et la fréquence de la douleur. Après l'approbation d'un comité d'éthique de la recherche, 1022 personnes recrutées pour participer à une étude menée à l'Ontario Science Centre de Toronto, en Ontario, ont donné leur autorisation ou leur consentement éclairé.

RÉSULTATS : Sur les 1006 participants (54\% de femmes, âge moyen [ \pm ÉT] de $11,6 \pm 2,7$ ans) qui avaient fourni des données complètes, $27 \%$ ont déclaré avoir ressenti de la douleur pendantau moins trois mois. Les chercheurs ont effectué une ANOVA multivariée $2 \times 2 \times 2$ (antécédents de douleur, âge et sexe), les indices totaux du CASI, de la CPASS, de la MASC-10 et de la PCS-C servant de variables dépendantes. Les filles ayant des antécédents de douleur persistante exprimaient des taux plus élevés de sensibilité à l'anxiété $(\mathrm{P}<0,001)$ et de catastrophisation de la douleur $(\mathrm{P}<0,001)$ que les filles n'ayant pas de tels antécédents et que les garçons, quels que soient leurs antécédents. Les chercheurs ont constaté le même schème de résultats relativement à l'anxiété et à l'anxiété de la douleur au sein du groupe plus âgé, mais pas du groupe plus jeune.

CONCLUSIONS : Les garçons et les filles semblent différents pour ce qui est du lien entre l'âge ainsi que les antécédents de douleur et l'expression des variables psychologiques liées à la douleur. Étant donné la prévalence de douleur persistante constatée dans l'étude, plus de recherches s'imposent sur les répercussions de la douleur persistante sur le développement pendant l'enfance et l'adolescence.

continuing pain $(2,5,6)$. Hence, it appears that persistent pain during childhood and adolescence is a widespread phenomenon.

Pediatric pain has important economic, social and psychological repercussions. Research conducted in the United Kingdom has found that costs associated with treating pediatric chronic pain are estimated to be $£ 8000$ (approximately CAD $\$ 13,000$ ) per patient (7). The presence of pain in children has been associated with lower self-reported quality of life (5), functional disability $(8,9)$, high emotional distress including symptoms of depression and anxiety (10), increased school absenteeism (11), elevated usage of health care services (12), impaired sleep (9) and poor self-rated health (4). The impact of chronic pain in children and adolescents goes beyond the individuals affected, with more than one-third of parents of children with pain reporting clinically significant levels of stress and 


\section{TABLE 1}

Demographic characteristics

\begin{tabular}{lc}
\hline Characteristic & \\
\hline Age, years, mean \pm SD & $11.6 \pm 2.7$ \\
Female sex & $545(54.2)$ \\
Ethnicity & \\
White & $605(60.1)$ \\
Other & $115(11.4)$ \\
East Asian & $73(7.3)$ \\
South Asian & $66(6.6)$ \\
African Canadian & $48(4.8)$ \\
African Caribbean & $40(4.0)$ \\
Middle Eastern & $27(2.7)$ \\
Hispanic/Latino & $25(2.5)$ \\
Aboriginal & $7(0.7)$ \\
Living with & \\
Both parents & $780(77.5)$ \\
One parent & $176(17.5)$ \\
Relatives & $26(2.6)$ \\
Other & $24(2.4)$ \\
\hline
\end{tabular}

Data presented as $n$ (\%) unless otherwise indicated

depression (10). The occurrence of persistent pain, therefore, has broad implications for a child's physical and emotional well-being, which extend to the immediate family environment.

Several constructs are believed to play important roles in the development and maintenance of persistent pain, including anxiety sensitivity, pain catastrophizing, and fear of pain or pain anxiety (13). Anxiety sensitivity is conceptualized as a fear of anxiety-related sensations stemming from a belief that such anxious feelings can lead to harmful emotional, social and physical consequences in and of themselves (14). Pain catastrophizing involves the tendency to ruminate and worry about pain-related sensations, to magnify the consequences of pain and to feel helpless in the face of pain (15). Pain anxiety encompasses somatic, cognitive, fearful, and escape or avoidance reactions to pain (16). Fear-avoidance models of chronic pain are instrumental to our understanding of pain-related disability in adults, and this conceptualization of disability has been extended to pediatric populations $(13,17)$. It has been suggested that individuals who exhibit high levels of anxiety sensitivity, pain catastrophizing and pain anxiety tend to react to pain in a state characterized by hyperarousal and hypervigilance, which increases the tendency to engage in avoidance or escape (13). This avoidance can lead to inactivity and disuse of pain-affected areas and, in turn, deconditioning of muscular and skeletal structures, which is likely to result in increased pain in the future (13). Consistent with this conceptualization, anxiety sensitivity and pain anxiety were shown to relate significantly to pain disability in a sample of children and adolescents with chronic pain (17). Consequently, there appears to be a considerable need to investigate the relevance of these constructs in child and adolescent populations.

Many pain-related psychological factors have been examined in chronic pediatric pain samples, and this research has provided a strong basis for understanding the complex and multifaceted experience of pain in childhood and adolescence. There is, however, a paucity of research that examines the experience of pain in nonclinical samples. Community-based research is necessary to uncover the way pain is experienced by young people, regardless of whether treatment is sought or available to them. The objectives of the present study were to ascertain the lifetime prevalence of pediatric pain in a Canadian, community-based sample, explore sex and age differences in the prevalence of pain, and examine how children and adolescents who report having experienced persistent pain differ from those who do not with respect to psychological variables including anxiety, anxiety sensitivity, pain anxiety and pain catastrophizing.

\section{METHOD}

\section{Participants}

Data were collected from 1022 children and adolescents who were between eight and 18 years of age (mean [ \pm SD] $11.6 \pm 2.7$ years). Twelve children withdrew from the study before completion; the partial data they provided were not used. The data from four other children were excluded because of obvious inaccuracies (eg, age input as 52 years). The final sample consisted of 1006 participants, $54.2 \%$ of whom were female. More than one-half of the participants identified themselves as white $(60.1 \%)$. The majority of participants lived with both parents $(77.5 \%)$. Table 1 summarizes the demographic characteristics of the sample.

\section{Procedure}

The present study was approved by the Research Ethics Board of York University (Toronto, Ontario) and the research division of the Ontario Science Centre in Toronto. The project was conducted at the Ontario Science Centre during a four-week period in the summer of 2009. The Ontario Science Centre is an interactive science-based museum open to the public. It was selected as the setting for the present research because it provides access to an ethnically and culturally diverse sample of individuals. The Ontario Science Centre limits the duration of studies to approximately $20 \mathrm{~min}$. Accordingly, the research protocol was designed to take approximately $20 \mathrm{~min}$ to complete. The intention was to recruit 1000 participants (approximately 250 participants per week). Child and adolescent visitors between eight and 18 years of age, accompanied by a parent or guardian, were approached by a research team member who provided them with information about the study. Parents or guardians, and their children, who expressed an interest in participating were led into the testing room. Informed consent was obtained from each parent or guardian before his or her child participated in the study. Verbal assent was also obtained from each child before beginning the study. Participants were helped by their parents/guardians or research assistants if any clarification regarding the questions was needed. All self-report questions were administered to the participants using laptop computers equipped with MediaLab Research Software (version 2006.2.40, Empirisoft Corporation, USA). Computer administration of questionnaires has been shown to be as reliable and valid in child and adolescent samples as traditional paper-based methods (18). Participants began by answering basic demographic questions (age, sex, ethnicity and living arrangements) followed by pain history questions. Participants then completed the following questionnaires: the Childhood Anxiety Sensitivity Index (CASI), the Child Pain Anxiety Symptoms Scale (CPASS), the Multidimensional Anxiety Scale for Children-10 (MASC-10) and the Pain Catastrophizing Scale for Children (PCS-C). The order of questionnaire administration was randomized for each participant using the built-in randomization feature of MediaLab Research Software.

\section{Measures}

CASI: The CASI (19) is an 18-item scale that assesses anxiety sensitivity or the fear of anxiety-related sensations, adapted for use in children from the original ASI (20). Individuals are asked to rate how much they agree with each item on the basis of their own experience, from 1 (none) to 3 (a lot). If a particular item is a sensation or feeling that an individual is not familiar with, he or she is asked to rate the item according to how he or she would imagine responding if such a sensation or feeling occurred. Total scores range from 18 to 54 . The CASI has been shown to have a satisfactory test-retest reliability $(\mathrm{r}=0.76$ to 0.79$)$ and good internal consistency $(\alpha=0.87)$ (19). Moreover, scores on the CASI have been shown to correlate significantly with panic and agoraphobia-related symptoms of anxiety $(\mathrm{r}=0.71)$, indicating strong construct validity (21).

CPASS: The CPASS (22) is a modified version of the 20-item version of the PASS (23) designed to assess pain-specific responses to fear and 
TABLE 2

\section{Pain characteristics for total sample}

\begin{tabular}{lc}
\hline Variable & $\mathbf{n}(\%)$ \\
\hline Pain persisting longer than 3 months & \\
Yes & $268(26.6)$ \\
No & $738(73.4)$ \\
Pain frequency & \\
No pain & $186(18.5)$ \\
Less than once a month & $293(29.1)$ \\
Once or twice a month & $277(27.5)$ \\
Once or twice a week & $191(19.0)$ \\
Every day & $59(5.9)$ \\
\hline
\end{tabular}

anxiety in children as young as eight years of age. Each item is rated on a scale from 0 (never) to 5 (always), for a total score ranging from 0 to 100. Preliminary results suggest that the CPASS has good internal consistency ( $\alpha=0.89$ to 0.903 ), strong construct validity (correlates with the PCS-C), good discriminant validity (shows only modest correlations with the MASC-10) and strong concurrent validity (significantly associated with pain frequency) (22). The data for the validation study (22) of the CPASS came from the same sample as the present study.

MASC-10: The MASC-10 $(24,25)$ is a shortened version of the original 39-item self-report measure that assesses anxiety symptoms in children and adolescents. The MASC-10 contains questions pertaining to physical symptoms of anxiety, social anxiety, harm avoidance and separation anxiety. Children rate the extent to which each of the statements is true about them on a scale from 0 (never true about me) to 3 (often true about me). The MASC-10 has good internal consistency $(\alpha=0.89)$, high test-retest reliability $(r=0.86)$, good convergent validity (high correlation with other anxiety measures such as the Revised Children's Manifest Anxiety Scale) and good discriminant validity (no significant correlation with depression measures such as the Children's Depression Inventory) (24).

PCS-C: The PCS-C (26) is a 13-item self-report measure that assesses the tendency to catastrophize about pain. The scale has been modified from the original PCS (Sullivan et al [15]) and adapted for use in children. Each item describes a thought or feeling that individuals may have when they are in pain, and is rated from 0 (not at all) to 4 (extremely). Total scores range from 0 to 52. Preliminary results suggest that the PCS-C has good internal consistency $(\alpha=0.90)$ and correlates highly with pain intensity $(\mathrm{r}=0.49)$ and disability $(\mathrm{r}=0.50)$.

Pain history questions: Three questions were used to assess the pain history and pain frequency characteristics of the participants. The first question was used to examine rates of persistent pain ("Have you ever had pain that lasted for three months or longer?"). If individuals answered "yes" rather than "no" to this question, they were prompted to an open-ended question asking them to describe the nature of this pain ("What type of pain was it?"). All individuals were then asked to describe how frequently they experienced pain from a fixed set of descriptors ("less than once a month, once or twice a month, once or twice a week, everyday, or no pain").

Data analysis

All data were analyzed using SPSS (version 17.0.2, IBM Corporation, USA). $\chi^{2}$ tests were used to examine the presence of sex and age differences in the rates of persistent pain and average frequency of pain experienced. A $2 \times 2 \times 2$ (pain history [persistent pain, no persistent pain], age [median split: eight to 11 years, 12 to 18 years] and sex [boys, girls]) multivariate ANOVA (MANOVA) was conducted, with the total scores on the CASI, the CPASS, the MASC-10 and the PCS-C as dependent variables. Significant findings from the MANOVA were followed up with univariate ANOVAs. The magnitude of each effect was examined using partial $\eta^{2}$. Significant interaction effects were decomposed using simple effects with a Bonferroni
TABLE 3

Frequency distribution of sample according to age, sex and pain group

\begin{tabular}{llcc}
\hline \multirow{2}{*}{ Age } & Pain & \multicolumn{2}{c}{$\mathbf{n ~ ( \% )}$} \\
\cline { 3 - 4 } Younger & Persistent pain & $64(6)$ & Girls \\
& No persistent pain & $200(20)$ & $210(21)$ \\
\multirow{2}{*}{ Older } & Persistent pain & $65(7)$ & $73(7)$ \\
& No persistent pain & $132(13)$ & $196(19)$ \\
\hline
\end{tabular}

correction to control for multiple comparisons. As recommended by Tabachnick and Fidell (27), before computing the MANOVA, $\mathrm{F}_{\max }$ ratios were used to assess for possible violations of the homogeneity of variance assumption. To calculate an $\mathrm{F}_{\max }$ ratio, the largest cell variance is divided by the smallest cell variance, and a quotient of $\geq 3$ suggests that the assumption of homogeneity of variance has been violated when sample sizes between groups are unequal (27). All $F_{\max }$ ratios were found to be $<3$. Data are presented as mean \pm SD unless otherwise indicated.

Pain characteristics

\section{RESULTS}

Table 2 displays a summary of pain prevalence and frequency characteristics. Approximately $27 \%(n=268)$ of the sample reported having experienced pain that persisted for three months or longer. On examining the types of persistent pain reported, it became clear that participants tended to use either sensory descriptors or bodily locations to classify their pain. Almost one-quarter (23\%) of those reporting having experienced persistent pain described their pain using sensory descriptors without identifying a bodily location (eg, "aching", "dull" or "sore"). Of those who reported experiencing persistent pain, the types/locations of persistent pain reported were diverse: $16 \%$ reported pain in the lower limbs, $10 \%$ reported pain in the head, face or mouth, $8 \%$ reported pain in the upper shoulders or limbs, $5 \%$ reported abdominal pain, $4 \%$ reported pain in the thoracic region, $3 \%$ reported pain in the lower back or spine, $2 \%$ reported pain in the cervical region and less than $1 \%$ reported pain in the anal or genital region. In addition, $15 \%$ reported pain of an emotional nature (eg, "sadness", "feeling empty" or "depression") and 13\% of the sample did not specify the origin or type of pain experienced. The subsequent data analyses were performed with the emotional pain and unspecified groups both removed and included. There were no significant differences in terms of findings; therefore, these groups remained in the analyses.

\section{Sex, age, pain prevalence and pain frequency}

$\chi^{2}$ tests were used to examine sex and age differences in the prevalence of persistent pain and average pain frequency. Prevalence differences were found for boys but not for girls, with a significantly greater number of older boys (12 to 18 years of age) reporting having experienced persistent pain compared with younger boys $\left(\chi^{2}[1,1, \mathrm{n}=1006]=4.29, \mathrm{P}=0.05\right)$. Table 3 presents the number and proportion of the total sample in each group. Significant age differences in pain frequency were not found for boys $\left(\chi^{2}[4,1, \mathrm{n}=1006]=3.01, \mathrm{P}=0.56\right)$ or for $\operatorname{girls}\left(\chi^{2}[4,1, \mathrm{n}=1006]=4.48\right.$, $\mathrm{P}=0.35)$. Significant sex or age differences were not found for the type of pain reported.

\section{Pain history, age and sex differences according to psychological} variables

A $2 \times 2 \times 2$ (pain history [persistent pain, no persistent pain], age [median split: eight to 11 years, 12 to 18 years] and sex [boys, girls]) MANOVA revealed a significant main effect of pain history (Wilks' $\Lambda=0.98$, $F[4,995]=5.7, P<0.001, \eta^{2}=0.022$ ), sex (Wilks' $\Lambda=0.94, F[4,995]=14.1$, $\mathrm{P}<0.001, \eta^{2}=0.056$ ) but not age (Wilks' $\Lambda=0.99, \mathrm{~F}[4,995]=1.4, \mathrm{P}=0.23$ ). Significant effects were found for the three-way pain history $\times$ age $\times$ sex 
TABLE 4

Summary of univariate ANOVAs

\begin{tabular}{|c|c|c|c|c|c|c|}
\hline Source & SS & df & MS & $F$ & $\mathbf{P}$ & $\eta^{2}$ \\
\hline \multicolumn{7}{|l|}{ CASI } \\
\hline Age & 0.00 & 1,930 & 0.00 & 0.00 & 0.9 & \\
\hline Sex & 1428.1 & 1,930 & 1428.1 & 39.4 & $<0.001$ & 0.04 \\
\hline Pain history & 325.4 & 1, 930 & 325.4 & 8.9 & 0.003 & 0.01 \\
\hline Sex $\times$ pain history & 257.0 & 1,930 & 257.0 & 7.1 & 0.01 & 0.01 \\
\hline Age $\times$ sex $\times$ pain history & 73.8 & 1,930 & 73.8 & 2.0 & 0.15 & \\
\hline \multicolumn{7}{|l|}{ CPASS } \\
\hline Age & 106.3 & 1,930 & 106.3 & 0.6 & 0.41 & \\
\hline Sex & 4017.1 & 1,930 & 4017.1 & 15.7 & $<0.001$ & 0.03 \\
\hline Pain history & 738.6 & 1,930 & 738.6 & 2.8 & 0.09 & \\
\hline Sex $\times$ pain history & 117.9 & 1,930 & 117.9 & 0.5 & 0.1 & \\
\hline Age $\times$ sex $\times$ pain history & 1746.5 & 1,930 & 1746.5 & 6.8 & 0.01 & 0.01 \\
\hline \multicolumn{7}{|l|}{ MASC } \\
\hline Age & 65.5 & 1,930 & 65.5 & 2.1 & 0.3 & \\
\hline Sex & 945.6 & 1, 930 & 945.6 & 30.2 & $<0.001$ & 0.03 \\
\hline Pain history & 18.9 & 1,930 & 18.9 & 0.6 & 0.44 & \\
\hline Sex $\times$ pain history & 24.4 & 1,930 & 24.4 & 0.8 & 0.38 & \\
\hline Age $\times$ sex $\times$ pain history & 329.8 & 1,930 & 329.8 & 10.5 & 0.001 & 0.01 \\
\hline \multicolumn{7}{|l|}{ PCS-C } \\
\hline Age & 129.0 & 1,930 & 129.0 & 1.3 & 0.26 & \\
\hline Sex & 3508.6 & 1,930 & 3508.6 & 34.4 & $<0.001$ & 0.04 \\
\hline Pain history & 1296.3 & 1, 930 & 1296.3 & 12.7 & $<0.001$ & 0.01 \\
\hline Sex $\times$ pain history & 378.9 & 1,930 & 378.9 & 3.7 & 0.05 & 0.004 \\
\hline Age $\times$ sex $\times$ pain history & 229.7 & 1,930 & 229.7 & 2.3 & 0.13 & \\
\hline
\end{tabular}

CASI Childhood Anxiety Sensitivity Index; CPASS Child Pain Anxiety Symptoms Scale; MASC-10 Multidimensional Anxiety Scale for Children-10; PCS-C Pain Catastrophizing Scale for Children

interaction (Wilks' $\Lambda=0.99, F[4,995]=2.48, P=0.04, \eta^{2}=0.01$ ), two-way pain history $\times$ sex interaction (Wilks' $\Lambda=0.98, F[4,995]=5.5, P<0.001$, $\eta^{2}=0.022$ ), the age $\times$ sex interaction (Wilks' $\Lambda=0.99, F[4,995]=2.5$, $\mathrm{P}=0.04, \eta^{2}=0.011$ ), but not the age $\times$ pain history interaction (Wilks' $\Lambda=0.99, \mathrm{~F}[4,995]=0.323, \mathrm{P}=0.86$ ).

Table 4 presents a summary of the univariate ANOVAs. The pattern of univariate ANOVA results was the same for the CASI and PCS-C; namely, a significant main effect of sex, pain history, and a significant two-way sex $\times$ pain history interaction effect. As shown in Figure 1, girls with a history of persistent pain had significantly higher scores on the CASI $(31.2 \pm 7.5)(\mathrm{F}[1,998]=15.8, \mathrm{P}<0.001)$ and PCS-C $(22.9 \pm 11.7)(\mathrm{F}[1,998]=20.2, \mathrm{P}<0.001)$ than girls without a history of persistent pain (CASI: $28.7 \pm 5.9$, PCS-C: $18.8 \pm 10.1$ ), whereas boys did not differ significantly according to pain history on the CASI $(F[1,998]=0.125, P=0.72)$ or the PCS-C $(F[1,998]=2.7, P=0.09)$. The two-way interaction effect was also examined by comparing sex within pain history. Among participants with a history of persistent pain, girls had significantly higher scores than boys on the CASI $(F[1,1003]=28.1$, $\mathrm{P}<0.001)$ and the PCS-C $(\mathrm{F}[1,998]=23.5, \mathrm{P}<0.001)$. Among participants without a history of persistent pain, girls had significantly higher scores than boys on the CASI $(F[1,1003]=12.0, P=0.001)$ and the PCS-C $(F[1,998]=11.31, P=0.001)$.

The pattern of significant univariate ANOVA effects was the same for the CPASS and the MASC-10; namely, a significant main effect of sex, and a significant three-way age $\times \operatorname{sex} \times$ pain history interaction. For the CPASS, the effects of sex and pain history were significant in both the younger $(F[3,998]=5.02, P=0.002)$ and the older age groups $(\mathrm{F}[3,998]=7.88, \mathrm{P} \leq 0.001)$. An analysis of simple effects according to age group revealed several significant findings. As shown in Figure 2 (top panel), in the younger age group (eight to 11 years), girls without a history of persistent pain $(30.3 \pm 16.6)$ had significantly higher scores than boys without a history of persistent pain $(24.2 \pm 15.6),(\mathrm{P}=0.001)$

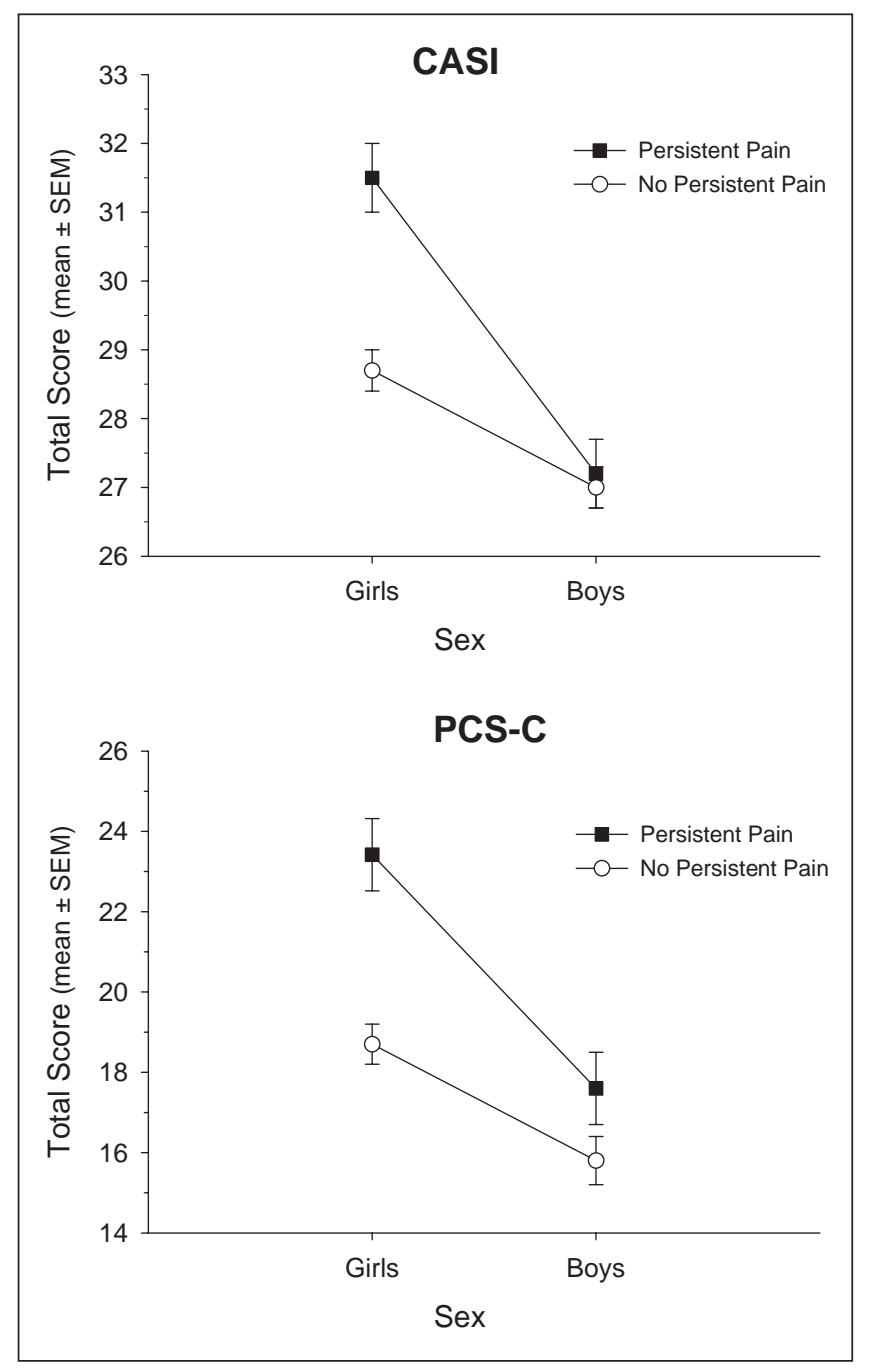

Figure 1) Mean \pm SEM scores on the Childhood Anxiety Sensitivity Index (CASI) and the Pain Catastrophizing Scale for Children (PCS-C) according to pain history and sex. Girls with a history of persistent pain had significantly higher scores on the CASI and PCS-C than girls without a history of persistent pain. Boys did not differ significantly according to pain history. Note that the range of scores, which does not include 0 , has been restricted to facilitate plotting

whereas boys and girls with persistent pain did not differ significantly. As shown in Figure 2 (bottom panel), in the older age group (12 to 18 years), girls with a history of persistent pain $(33.5 \pm 19.8)$ had significantly higher scores on the CPASS than boys with $(24.7 \pm 13.5)$ and without $(22.7 \pm 14.5)$ a history of persistent pain (all $\mathrm{P} \leq 0.01$ ). Finally, among adolescents without a history of persistent pain in the older age group, girls $(28.4 \pm 14.4)$ had significantly higher scores than boys $(23.1 \pm 14.5, \mathrm{P}=0.01)$.

For the MASC-10, the effects of sex and pain history were significant in both the younger $(\mathrm{F}[3,998]=5.23, \mathrm{P}=0.001)$ and the older age groups $(\mathrm{F}[3,998]=10.35, \mathrm{P} \leq 0.001)$. As shown in Figure 3 (top panel), in the younger age group, girls without a history of persistent pain had significantly higher scores $(11.6 \pm 5.9)$ than boys without a history of persistent pain $(9.9 \pm 4.6)(\mathrm{P} \leq 0.001)$, whereas boys and girls in the persistent pain group did not differ significantly. In the older age group (Figure 3, bottom panel), girls with a history of persistent pain $(13.3 \pm 6.7)$ had significantly higher scores on the MASC-10 than both boys with $(8.0 \pm 4.6)$ and without $(9.4 \pm 4.9)$ a history of persistent pain (all $\mathrm{P} \leq 0.001$ ). 


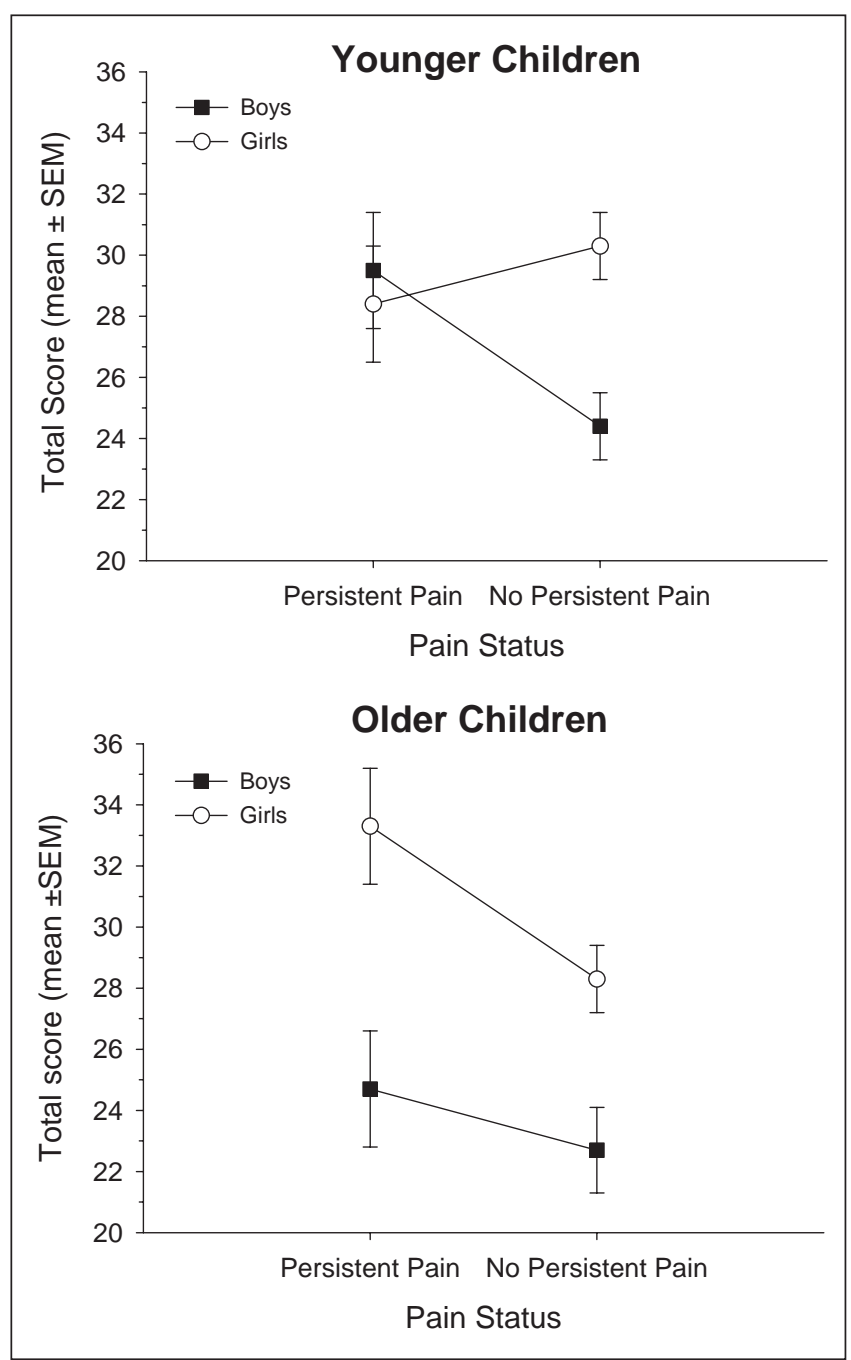

Figure 2) Mean \pm SEM scores on the Child Pain Anxiety Symptoms Scale (CPASS) according to age, sex and pain history. In the younger age group (eight to 11 years), girls with no history of persistent pain had significantly higher scores than boys with the same pain history. In the older age group (12 to 18 years), girls with a history of persistent pain had significantly higher scores than boys with the same pain history as well as boys with no history of persistent pain. Note that the range of scores, which does not include 0 , has been restricted to facilitate plotting

\section{DISCUSSION}

The purpose of the present study was to examine the lifetime prevalence of, and psychological variables associated with, persistent pain in a Canadian community sample of children and adolescents. The results demonstrate that the rate of persistent pain $(27 \%)$ is consistent with previously conducted epidemiological research in child and adolescent community samples (2,11). Van Dijk et al (4) reported a much lower chronic pain prevalence rate of $5 \%$ in their study of Canadian children. This disparity, however, is likely attributed to differences in pain classification because they assessed point prevalence, classifying pain as chronic if it had lasted for a few months and was still present at the time of the study. The rate of persistent pain in the present sample is comparable with estimates of pain in adult populations. Research using stratified sampling has found that approximately $17 \%$ to $45 \%$ of adults have experienced an episode of chronic pain lasting three months or longer (28-30). It appears that persistent pain during childhood and adolescence is not a rare occurrence; however, there are definite gaps in our understanding of the time course of pain and

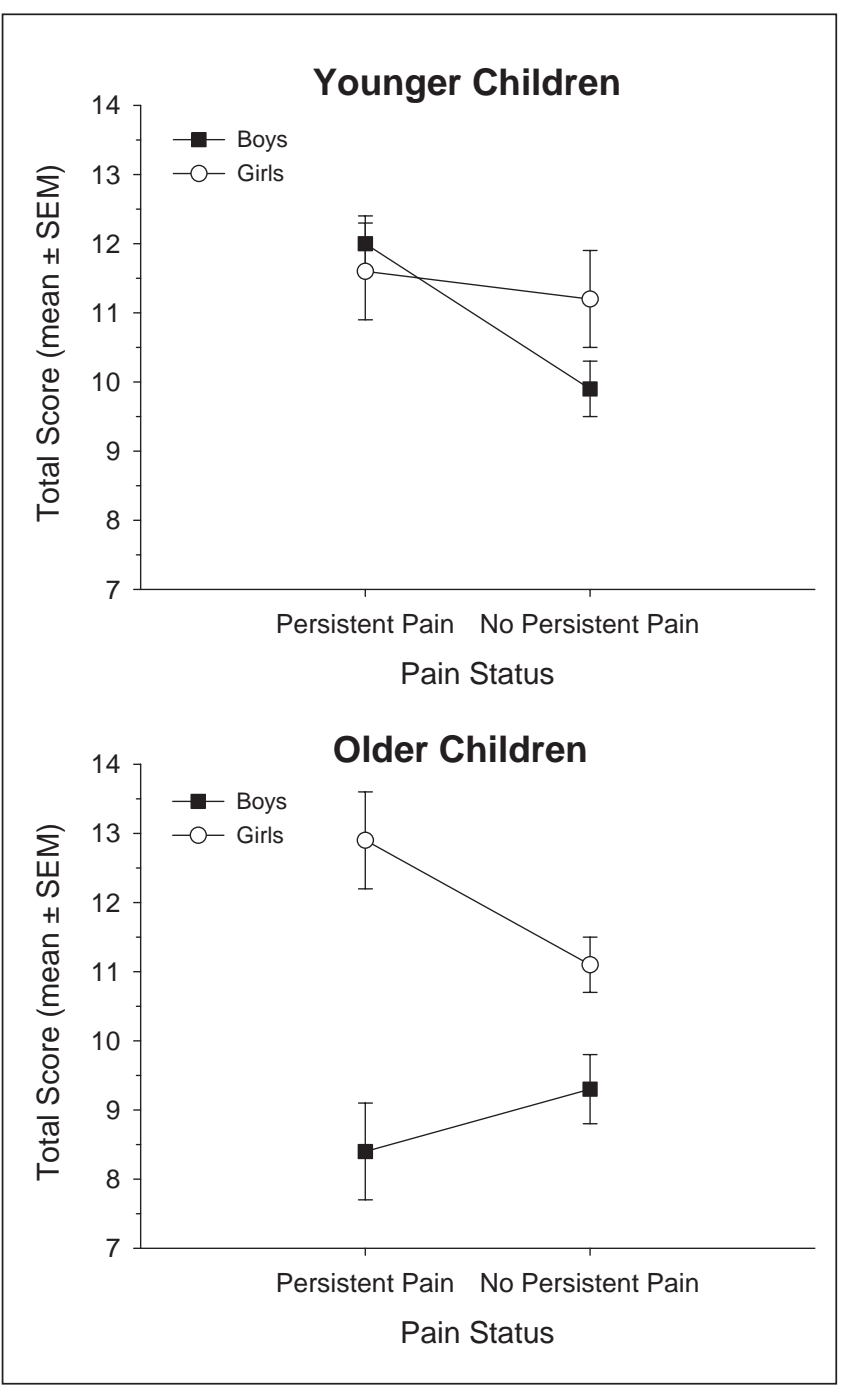

Figure 3) Mean \pm SEM scores on the Multidimensional Anxiety Scale for Children-10 (MASC-10) according to age, sex and pain history. In the younger age group, girls with no history of persistent pain had significantly higher scores than boys with no history of pain. In the older age group, girls with a history of persistent pain had significantly higher scores than both boys with and without a history of pain. Note that the range of scores, which does not include 0 , has been restricted to facilitate plotting

developmental trajectories within children and adolescents. For instance, little is known about how the presence of persistent pain in these life stages relates to pain experiences as an adult. A cohort-based study found that individuals who had experienced recurrent headaches as children were more likely to report having headaches and other physical symptoms in adulthood than those who did not report such pain during childhood (31). Prospective, longitudinal research is needed to ascertain the extent to which various types of persistent pain experienced during childhood and adolescence are risk factors for the development of chronic pain in adulthood.

Unlike a number of previous studies, the present sample did not exhibit significant sex differences in the prevalence of persistent pain or the frequency characteristics with which pain is experienced $(2,6,32)$. It is important to note, however, that other large-scale Canadian epidemiological studies have also failed to find such a sex disparity in the prevalence of persistent pain $(4,33)$. This lack of a sex effect in the present study could be due, in part, to differences between community-based and hospital- or clinic-based samples. Sex 
differences in health care use are fairly well established, and these disparities have also been found in child and adolescent samples, with girls being more likely to seek care for illness and pain than boys (34-36). If girls solicit medical treatment for pain more often than boys, they may become overrepresented in hospital and clinic settings. In 2009, Fillingim et al (37) reviewed the evidence for sex differences across a number of pain conditions and noted that a sex disparity within children and adolescents tends to emerge only after the onset of puberty. Given this assertion, we expected to find a greater proportion of older girls reporting persistent pain compared with younger girls, which was not the case. A number of different factors, including the research setting as well as the age distribution of the study sample, therefore, could influence whether a sex difference in pain prevalence is likely to emerge. The notion that girls are more likely to experience persistent pain than boys appears to warrant further investigation.

In contrast to the absence of sex differences in pain prevalence, differences in sex and pain history were found for anxiety sensitivity and pain catastrophizing across age groups, and for general anxiety and pain anxiety, when age group was taken into account. Overall, girls had higher levels of anxiety sensitivity and pain catastrophizing than boys. With regard to general anxiety and pain anxiety amongst the older age group (12 to 18 years), girls with a history of persistent pain had significantly higher scores than those without a pain history, but this was not the case for boys. Even girls without a history of pain expressed higher levels of anxiety, anxiety sensitivity, pain anxiety and pain catastrophizing than boys. According to the diathesis-stress model of chronic pain and disability, anxiety sensitivity is a vulnerability factor (diathesis) that contributes to a greater likelihood of responding to injury and other pain experiences (stress) with catastrophic thinking and greater fear of pain, which in turn, affect function and disability through avoidance (38). In the present study, anxiety sensitivity levels did not differ significantly according to age group. Consistent with this finding, anxiety sensitivity has been shown to remain fairly stable over time, with adolescents maintaining high or low levels, suggesting the construct to be trait rather than state based (39). Given the welldocumented findings of a sex difference in pain prevalence in the adult literature (37), the absence of a similar effect in the present sample, coupled with the presence of a difference in anxiety sensitivity between boys and girls, introduces the possibility that the pre-existing higher levels of anxiety sensitivity among girls will ultimately contribute to a greater prevalence as they are inevitably exposed to everyday injuries and/or other painful events. Only longitudinal research can address whether these psychological factors represent developmental vulnerabilities or are consequences of pain and become exacerbated as a result of a pain-related condition. Future research might test the relationships between anxiety sensitivity, pain anxiety and pain catastrophizing amongst girls with a history of persistent pain and whether this model applies to boys.

The results of the present study indicate that boys with and without a history of persistent pain did not differ in their expression of these pain-related psychological constructs, suggesting that current models of chronic pain may not pertain to both sexes equally. While it is necessary to acknowledge that such models were originally developed to explain how chronic pain is maintained in clinical adult populations, it seems likely that similar mechanisms should apply to children and adolescents. Interestingly, such sex differences are partly congruent with research in adults. In general, women have been shown to respond to pain with greater negative affectivity than men (40). A study of individuals with chest pain (41) found that anxiety sensitivity was related to pain only in women. Similarly, pain catastrophizing has been shown to contribute uniquely to the experience of experimentally induced acute pain in women but not in men (42). Using a cold pressor task, Sullivan et al (42) found that levels of pain catastrophizing related significantly only to women's pain ratings. Girls have been shown to use more emotion-focused coping strategies than boys in the face of pain (43). From a developmental perspective, cognitive or affective responses to pain appear to differ according to sex within childhood and adolescence. Whether these differences are socially or biologically driven is unknown, but the notion that they may not be as relevant to the pain experiences of boys requires further study.

While several significant differences according to age, sex and pain history were found on all the measures in the present study, the magnitude of each of these effects was small. Using partial $\eta^{2}$, the differences between these groups, although significant, accounted for only a small proportion of variance ( $1 \%$ to $5 \%$ ). There may be several reasons for this discrepancy between significant findings and very small effects. We used a community, rather than a clinical or psychiatric sample, and, as such, it would be expected that the degree of difference between groups would not necessarily be dramatic or extreme. The constructs of interest to the present study exist on a continuum and are expressed to some degree by everyone. The results of the present study, nonetheless, provide valuable normative information for all of the variables assessed. Although the differences between groups may have been small, important patterns of findings did, indeed, emerge.

The present study does have limitations. First, all data were obtained through self-report without external validation from parents or health care professionals. Second, the project was cross-sectional and inferences cannot be drawn with regard to the temporal relationship between persistent pain and the psychological variables that were assessed. Finally, conducting the present project at the Ontario Science Centre and using a convenience sample had both benefits and drawbacks in terms of the generalizability of the study findings. Due to time constraints, we were unable to include additional questions relating to socioeconomic status and other important demographic factors such as whether individuals were from urban or rural areas. Nonetheless, given the ethnic diversity of our sample, it does not appear that there is any reason to believe that our sample differs dramatically from the population at large. However, the price of admission to the Ontario Science Centre ( $\$ 18$ for adults and $\$ 11$ for children) may be an obstacle for certain segments of the population.

\section{SUMMARY}

The results of the present study show persistent pain in Canadian youth to be fairly common, and the lifetime prevalence rate to be consistent with estimates in other child and adult populations. Male and female children and adolescents appear to express the psychological constructs associated with pain in a different manner, with the latter higher than the former on all measures except in the younger age group for which girls and boys did not differ in pain anxiety and general anxiety. The applicability of current models of persistent pain to both sexes appears to warrant further investigation.

ACKNOWLEDGEMENTS: Samantha Fuss and Gabrielle Pagé are supported by Canada Graduate Scholarships - Doctoral Awards from the Canadian Institutes of Health Research, and are Strategic Training Fellows in Pain: Molecules to Community. Gabrielle Pagé is a recipient of a Lillian Wright Maternal-Child Health Graduate Scholarship from York University. Joel Katz is supported by a Canadian Institutes of Health Research Canada Research Chair in Health Psychology. The authors thank Suzy Malakhi, Sarah Ritvo and the staff at the Ontario Science Centre for their help with this study. This article was derived, in part, from Samantha Fuss' Masters Thesis.

\section{REFERENCES}

1. Huguet A, Miró J. The severity of chronic pediatric pain: An epidemiological study. J Pain 2008;9:226-36.

2. Perquin CW, Hazebroek-Kampschreur AAJM, Hunfeld JAM, et al. Pain in children and adolescents: A common experience. Pain 2000;87:51-8.

3. Perquin CW, Hunfeld JAM, Hazebroek-Kampschreur AAJM, et al. The natural course of chronic benign pain in childhood and adolescence: A two-year population-based follow-up study. Eur J Pain 2003;7:551-9. 
4. van Dijk A, McGrath PA, Pickett W, VanDenKerkhof EG. Pain and self-reported health in Canadian children. Pain Res Manag 2008;13:407-11.

5. Hunfeld JAM, Perquin CW, Duivenvoorden HJ, et al. Chronic pain and its impact on quality of life in adolescents and their families. J Pediatr Psychol 2001;26:145-53.

6. Martin AL, McGrath PA, Brown SC, Katz J. Children with chronic pain: Impact of sex and age on long-term outcomes. Pain 2007;128:13-9.

7. Sleed M, Eccleston C, Beecham J, Knapp M, Jordan A. The economic impact of chronic pain in adolescence: Methodological considerations and a preliminary cost-of-illness study. Pain 2005;119:183-90.

8. Gauntlett-Gilbert J, Eccleston C. Disability in adolescents with chronic pain: Patterns and predictors across different domains of functioning. Pain 2007;131:132-41.

9. Konijnenberg AY, Uiterwaal CS, Kimpen JL, van der Hoeven J, Buitelaar JK, de Graeff-Meeder ER. Children with unexplained chronic pain: Substantial impairment in everyday life. Arch Dis Child 2005;90:680-6.

10. Eccleston C, Crombez G, Scotford A, Clinch J, Connell H. Adolescent chronic pain: Patterns and predictors of emotional distress in adolescents with chronic pain and their parents. Pain 2004;108:221-9.

11. Roth-Isigkeit A, Thyen U, Stoven H, Schwarzenberger J, Schmucker P. Pain among children and adolescents: Restrictions in daily living and triggering factors. Pediatrics 2005;115:e152-62.

12. Perquin CW, Hunfeld JAM, Hazebroek-Kampschreur AAJM, et al. Insights in the use of health care services in chronic benign pain in childhood and adolescence. Pain 2001;94:205-13.

13. Asmundson G, Norton P, Vlaeyen J. Fear-avoidance models of chronic pain: An overview. In: Asmundson G, Vlaeyen J, Crombez G, eds. Understanding and Treating Fear of Pain. New York: Oxford University Press, 2004:3-24.

14. Reiss S. Theoretical perspectives on the fear of anxiety. Clin Psychol Rev 1987;7:585-96.

15. Sullivan MJL, Bishop SR, Pivik J. The Pain Catastrophizing Scale: Development and validation. Psychol Assess 1995;7:524-32.

16. McCracken LM, Zayfert C, Gross RT. The Pain Anxiety Symptoms Scale: Development and validation of a scale to measure fear of pain. Pain 1992;50:67-73.

17. Martin AL, McGrath PA, Brown SC, Katz J. Anxiety sensitivity, fear of pain and pain-related disability in children and adolescents with chronic pain. Pain Res Manag 2007;12:267-72.

18. Young N, Varni J, Snider L, et al. The Internet is valid and reliable for child-report: An example using the Activities Scale for Kids (ASK) and the Pediatric Quality of Life Inventory (PedsQL). J Clin Epidemiol 2009;62:314-20.

19. Silverman WK, Fleisig W, Rabian B, Peterson RA. Childhood Anxiety Sensitivity Index. J Clin Child Adolesc Psychol 1991;20:162-8.

20. Reiss S, Peterson RA, Gursky DM, McNally RJ. Anxiety sensitivity, anxiety frequency and the prediction of fearfulness. Behav Res Ther 1986;24:1-8.

21. Muris P, Schmidt H, Merckelbach H, Schouten E. Anxiety sensitivity in adolescents: Factor structure and relationships to trait anxiety and symptoms of anxiety disorders and depression. Behav Res Ther 2001;39:89-100.

22. Pagé MG, Fuss S, Martin A, Romero Escobar M, Katz J. Development and preliminary validation of the Child Pain Anxiety Symptoms Scale in a community sample. J Pediatr Psychol 2010;35:1071-82.
23. McCracken LM, Dhingra L. A short version of the Pain Anxiety Symptoms Scale (PASS--20): Preliminary development and validity. Pain Res Manag 2002;7:45-50.

24. March JS, Parker JDA, Sullivan K, Stallings P, Conners CK. The Multidimensional Anxiety Scale for Children (MASC): Factor structure, reliability and validity. J Am Acad Child Adolesc Psychiatry 1997;36:554-65.

25. March JS, Sullivan K, Parker J. Test-retest reliability of the Multidimensional Anxiety Scale for Children. J Anxiety Disord 1999;13:349-58.

26. Crombez G, Bijttebier P, Eccleston C, et al. The child version of the pain catastrophization scale (PCS-C): A preliminary validation. Pain 2003;104:639-46.

27. Tabachnick BG, Fidell LS. Using Multivariate Statistics, 3rd edn. New York: HarperCollins College Publishers, 1996.

28. Blyth FM, March LM, Brnabic AJ, Jorm LR, Williamson M, Cousins MJ. Chronic pain in Australia: A prevalence study. Pain 2001;89:127-34.

29. Moulin DE, Clark AJ, Speechley M, Morley-Forster PK. Chronic pain in Canada - prevalence, treatment, impact and the role of opioid analgesia. Pain Res Manag 2002;7:179-84.

30. Tripp DA, VanDenKerkhof EG, McAlister M. Prevalence and determinants of pain and pain-related disability in urban and rural settings in southeastern Ontario. Pain Res Manag 2006;11:225-33.

31. Fearon P, Hotopf M. Relation between headache in childhood and physical and psychiatric symptoms in adulthood: National birth cohort study. BMJ 2001;322:1145.

32. Kaczynski KJ, Claar RL, Logan DE. Testing gender as a moderator of associations between psychosocial variables and functional disability in children and adolescents with chronic pain. J Pediatr Psychol 2009;34:738-48.

33. McDougall J, King G, De Wit DJ, et al. Chronic physical health conditions and disability among Canadian school-aged children: A national profile. Disabil Rehabil 2004;26:35-45.

34. Bertakis K, Azari R, Helms L, Callahan E, Robbins J. Gender differences in the utilization of health care services. J Fam Pract 2000;49:147-52.

35. Rudolf M, Tomanovich O, Greenberg J, Friend L, Alario A. Gender differences in infirmary use at a residential summer camp. J Dev Behav Pediatr 1992;13:261.

36. Unruh A. Gender variations in clinical pain experience. Pain 1996;65:123-67.

37. Fillingim RB, King CD, Ribeiro-Dasilva MC, Rahim-Williams B, Riley JL III. Sex, gender, and pain: A review of recent clinical and experimental findings. J Pain 2009;10:447-85.

38. Turk D. A diathesis-stress model of chronic pain and disability following traumatic injury. Pain Res Manag 2002;7:9.

39. Weems CF, Hayward C, Killen J, Taylor CB. A longitudinal investigation of anxiety sensitivity in adolescence. J Abnorm Psychol 2002;111:471-7.

40. Keogh EA. Negative affectivity, catastrophizing, and anxiety sensitivity. In: Asmundson GJG, Vlaeyen JWS, Crombez G, eds. Understanding and treating fear of pain. New York: Oxford University Press, 2004.

41. Keogh E, Hamid R, Hamid S, Ellery D. Investigating the effect of anxiety sensitivity, gender and negative interpretative bias on the perception of chest pain. Pain 2004;111:209-17.

42. Sullivan MJL, Tripp DA, Santor D. Gender differences in pain and pain behavior: The role of catastrophizing. Cognit Ther Res 2000;24:121-34.

43. Keogh E, Eccleston C. Sex differences in adolescent chronic pain and pain-related coping. Pain 2006;123:275-84. 


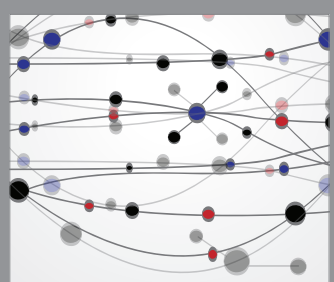

The Scientific World Journal
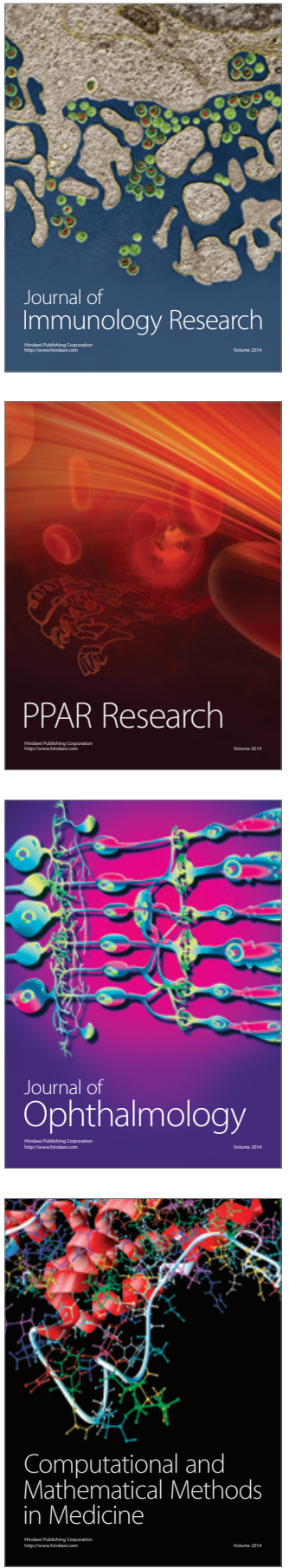

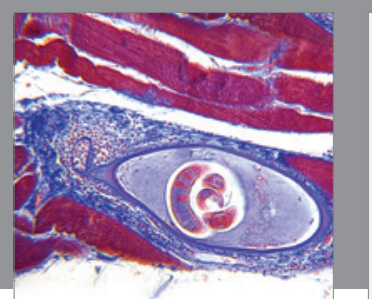

Gastroenterology Research and Practice

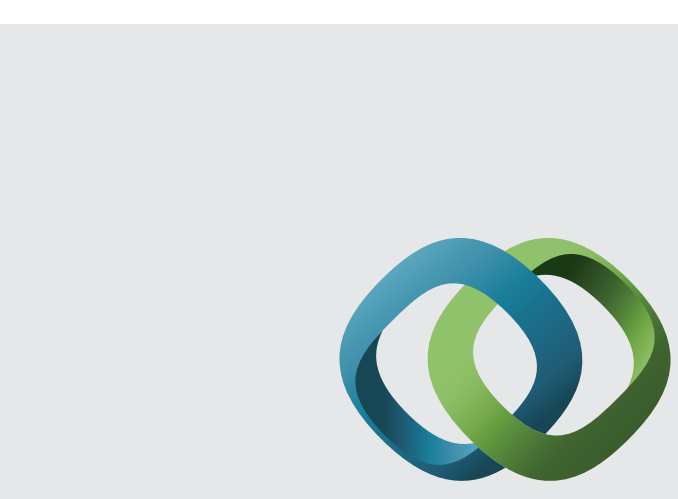

\section{Hindawi}

Submit your manuscripts at

http://www.hindawi.com
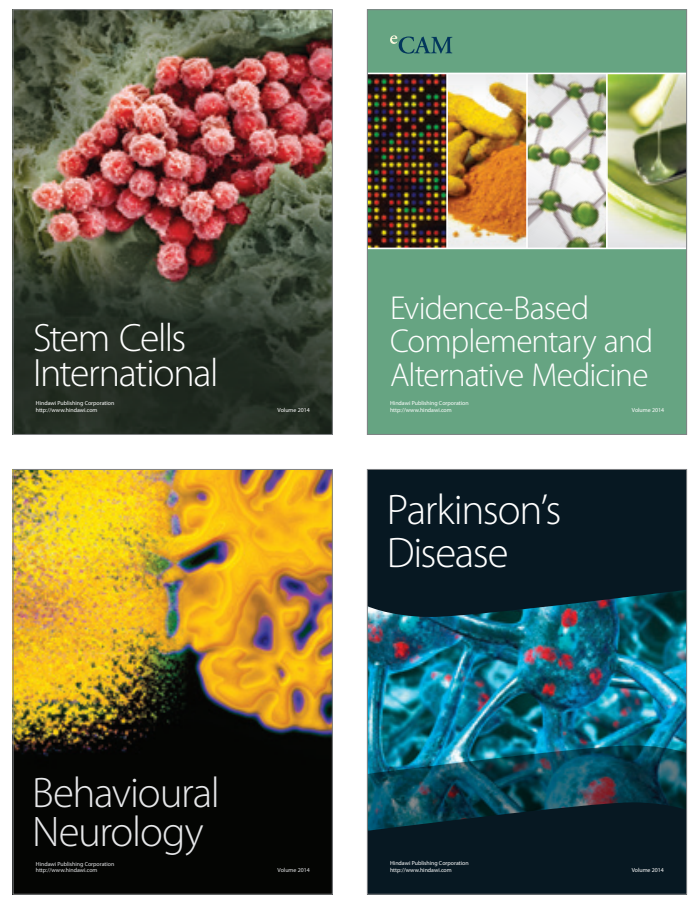
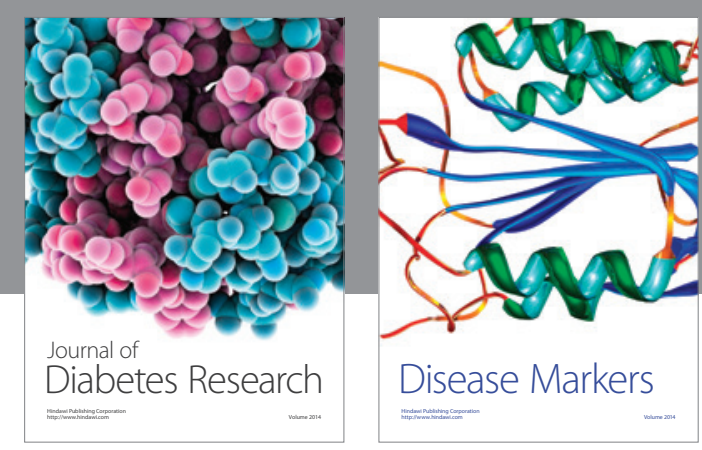

Disease Markers
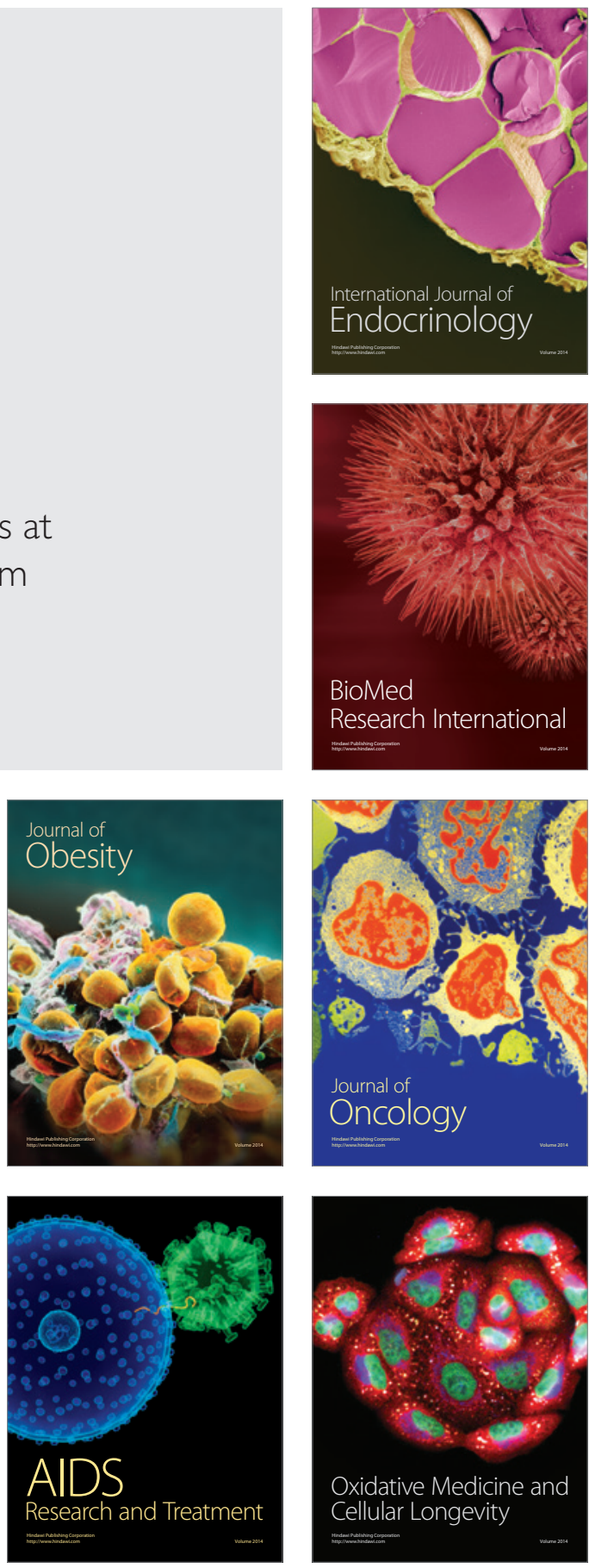